\title{
Quality Characteristics of a Refreshing Drink Based on Carob Pulp (Ceratonia siliqua)
}

\author{
Y.A. Marrugo-Ligardo ${ }^{1 *}$, C.A. Severiche-Sierra ${ }^{2}$, J. del C. Jaimes-Morales ${ }^{3}$, J.J. Lafont-Mendoza ${ }^{4}$, W. \\ Fong-Silva ${ }^{5}$ \\ ${ }^{1,2,3}$ Universidad de Cartagena, MAAS Research Group on Environment, Food and Health. Cartagena de indias, \\ Bolívar, Colombia. \\ ${ }^{4}$ Universidad de Córdoba, Research Group Organic Physicochemistry. Monteria, Cordoba, Colombia. \\ ${ }^{5}$ Universidad de Cartagena, GIMIFEC Research Group. Cartagena de indias, Bolívar, Colombia. \\ *correspondence author: ymarrugol@unicartagena.edu.co
}

\begin{abstract}
Carob tree (Ceratonia siliqua) and a legume tropical arboreal non-semi-arid, which is unwind in dry places, easily different power plants sobreviver. In this work the analysis of quality characteristics of a refreshing drink based on carob pulp (Ceratonia siliqua) was carried out, considering its standardization for this, physicochemical, microbiological, bromatological and sensorial analyzes of the obtained beverage were carried out. It is considered that the obtained beverage is within the established parameters, it is formulated for all types of people. The bromatological tests indicate significant presence of carbohydrates, vitamins and high content of carbon and potassium.
\end{abstract}

Keyword- Food technology, Legumes, Nutritional quality, Soda.

\section{INTRODUCTION}

Of the diversity of trees that exist in nature, carob trees are natural edible species that stand out from others because they have multiple attributes [1]. Not only do they provide human beings with food benefits, but also environmental benefits - forestry and represent an interesting agro-industrial potential given that all their parts can be taken advantage of in an integral way [2].

The carob tree (Ceratonia siliqua L.) is a Mediterranean tree, whose fruit, known as carob or carob, is an edible pod that is composed of $40-50 \%$ b weight of sweet carbohydrates, as well as dietary fiber rich in polyphenols [3]. According to Suleyman and Yusuf (2017) [4] Carob (Ceratonia siliqua) has been growing in the Mediterranean region for about 4,000 years. The world annual carob production is estimated at 310,000 $t$ from approximately 200,000 ha. In Turkey, annual carob production is approximately $13,500 \mathrm{t}$, obtained from 354,000 carob trees.

The carob pulp or flour is rich in pectin and simple (20 to 30\%), such as glicose, sacarose e frutose. Other constituents are: proteins, fat, flavonoids, mucilagens (3\%), tannins and mineral saps [5]. As sementes, das quais is prepared in gum, is rich in complex glycides like galactomannans (90\%) and hemicelluloses [6]. 41 phenolic compounds have been identified in the carob tree and it is affirmed that they can have a great antioxidant capacity [7].

The consumption by humans of this substance has a physiological impact on the gastrointestinal tract, since it has the ability to become viscous substances, sequester water, bind to bile salts and minerals, and can be degraded by the intestinal flora [8]. Therefore, it affects gastric emptying, excretion of bile salts, intestinal transit, absorption of nutrients, growth of intestinal flora and reduction of energy intake [9]. Dietary fibers are a vital part of a healthy diet, since fiber-rich diets could decrease the risk of certain noncommunicable diseases chronic diseases and these benefits are enhanced when this diet is associated with foods with low fat index [10].

The works on the development of refreshing drinks with pulps of Ceratonia siliqua, until now are beginning to be considered. The objective of this work has been to elaborate a refreshing drink of Carob considering its 
standardization for this, physicochemical, microbiological, bromatological and sensorial analyzes of the obtained beverage were carried out.

\section{Materials ANd Methods}

\section{Selection of raw material and standardization}

The raw material used was the carob tree (Ceratonia siliqua) tree that is born in tropical soils and in summer time. This fruit was collected in the outskirts of Magangué, Bolívar, in northern Colombia. It was done manually and stored at room temperature avoiding humidity, in Figure 1 the route is shown followed by a flow diagram that explains the process for the design and standardization of a refreshing drink.

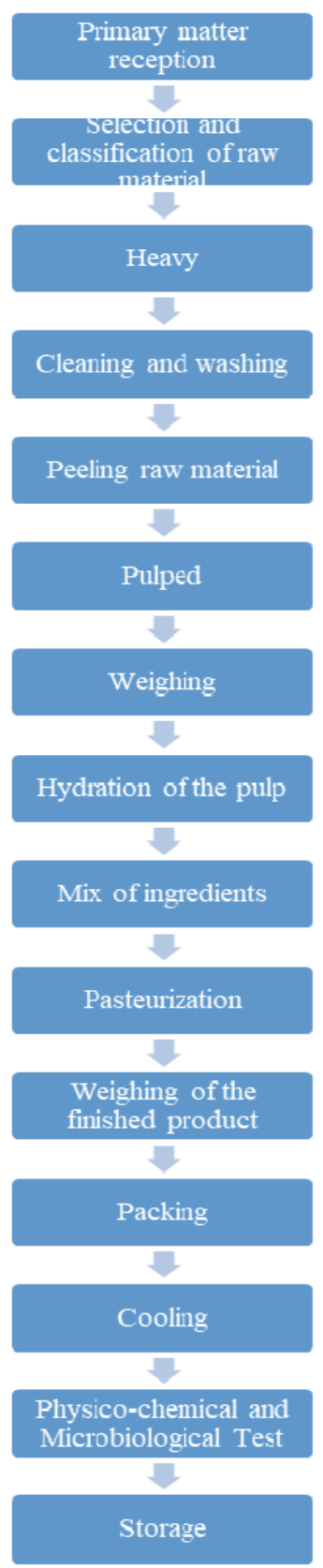

Figure I. Flowchart of the process for the design and standardization of a refreshing drink from the pulp of the carob tree (Ceratonia siliqua)

\section{Physico-chemical tests}

Determination of soluble solids: An aliquot of the product was taken, placed on the prism of the refractometer and then directly read the Brix or sugar content [11].

$\mathrm{pH}$ : The $\mathrm{pH}$ meter was introduced into a sample of $50 \mathrm{~mL}$ of food and the corresponding reading is taken [12]. 
Titratable acidity: $10 \mathrm{ml}$ of the sample was taken in a $100 \mathrm{~mL}$ beaker. 3 drops of phenolphthalein were added and the respective titration was made with $0.1 \mathrm{~N}$ sodium hydroxide [13].

\section{Microbiological tests}

For all the microbiological parameters the protocol established by Marrugo et al. (2017) [14] was followed.

For these tests the following culture media were used: Agares OGGY, VRBA, SPC, SPS.

Mesophil count: $1 \mathrm{~mL}$ of the direct sample was seeded 10th in duplicate. Then SPC agar was added and incubated at $37^{\circ} \mathrm{C}$ for $24-48$ hours. All the colonies were counted.

Total coliform count: $1 \mathrm{~mL}$ of direct sample was seeded $10^{\circ}$ in duplicate. Then we added VRB agar. We incubate at $37^{\circ} \mathrm{C}$ for $24-48$ hours. Colonies of purple color were counted.

Fecal coliform count: $1 \mathrm{~mL}$ of the direct sample was seeded at $10^{\circ}$, we added OGGY agar, and incubated at $22^{\circ}$ C.

Mold and yeast count: $1 \mathrm{~mL}$ of the direct sample was seeded at $10^{\circ} \mathrm{C}$. We added OGGY agar, and incubated at $22^{\circ} \mathrm{C}$. We leave at room temperature for 5 to 7 days.

Clostridium sulfite reductor: Clostridium sulphite reducing count. $1 \mathrm{~mL}$ was seeded in depth of the 10-4, 10-1 dilutions in duplicate. We add the SPS agar. We incubate at $37^{\circ} \mathrm{C}$ for $24-48$ hours.

\section{Bromatological tests}

Protein determination: The Kjeldahl method was used, in this the sample was treated by hot acid digestion in the presence of a catalyst [15]. Nitrogen was separated from the digestion products by direct steam entrainment and previous alkalization. Finally, the nitrogen was used by titration with $0.1 \mathrm{~N}$ sodium hydroxide solution.

Determination of fiber: Feeding fiber is understood as the amount of non-steerable material (cellulose) that contains a food [16]. It is the determination that is subjected in the previously degreased food material to a hydrolysis, acid followed by an alkalinity in order to solubilize substances such as proteins, carbohydrates, etc., are susceptible to this smooth hydrolysis [17].

Determination of sodium and potassium: the spectroscopic instruments of atomic absorption facilitate the analysis of most of the mineral elements. In the operation of these instruments, liquid materials are incinerated and re suspended liquid, which can be introduced directly into the device [18]. The solution passes through a flame that serves to dispense the molecules into individual atoms. The radiation of a cathode lamp passes through the flame, and the atoms absorb part of this radiation at specific lengths [19].

Determination of vitamin A, C, D: The instruments for this type of analysis were constructed in order to analyze almost all the compounds that are in liquid state. The sample to be examined is placed in the instrument and passed through a gas through a hot chromatography column [20]. This procedure allows the quantitative separation of closely related chemical compounds to be carried out rather quickly [21].

\section{Sensory tests}

For the sensory evaluation of the product, two types of tests were used: A so-called preference test for ordination, which consists of a number of selected judges or judges determining their degree of preference over three or more coded samples, in our case three in decreasing order. In this type of test, a single organoleptic characteristic is taken as a basis among the food samples under study [22]. The other test called preference is to ask the judge to say which of the two samples you prefer. To carry out this test, the questionnaire for preference test [23] was used.

\section{III.RESULTS AND DISCUSSION}

\section{Physicochemical analysis}

Table 1 shows the results of this analysis performed on the refreshing drink, it can be indicated that the $\mathrm{pH}$ is a parameter that determines not only the life of the product, but also gives a pleasant taste to the drink. The concentration of soluble solids or Brix complies with that established in national standards [24].

Table I. Physico-chemical analysis of the refreshing drink
\begin{tabular}{|c|c|c|c|}
\hline Sample & ${ }^{0}$ Brix & $\mathrm{pH}$ & Acidity \\
\hline Refreshing drink & 10.00 & 4.00 & 0.18 \\
\hline
\end{tabular}

\section{Microbiologic analysis}

For the microbiological tests, these were done days (10) days after having obtained the product, according to what can be seen in Table 2, in the product there was no presence of any kind of microorganisms, which makes the beverage developed be reliable and digestible for all the people who in one way or another wish to consume it [25]. 
Table II. Microbiological analysis of the refreshing drink

\begin{tabular}{|c|c|c|}
\hline Microbiological tests & Positive & Negative \\
\hline Counting of mesophilic microorganisms $/ \mathrm{mL}$ & & $\mathrm{X}$ \\
\hline NMP Totals coliforms $/ \mathrm{mL}$ & & $\mathrm{X}$ \\
\hline NMP Fecals coliforms/mL & & $\mathrm{X}$ \\
\hline Mushrooms and Yeast & & $\mathrm{X}$ \\
\hline Clostridium Sulfite-Fecals $/ \mathrm{mL}$ & & $\mathrm{X}$ \\
\hline
\end{tabular}

\section{Bromatological analyzes}

The bromatological results of the drink are recorded in Table 3, these indicate that the beverage has a high content of sugar, minerals and vitamins. Which means that it is a healthy drink because it fulfills a specific function of energy contribution, especially the content of carbohydrates, solids and potassium.

Table III. Bromatological results of the refreshing drink

\begin{tabular}{|c|c|}
\hline Parameters & Measurements \\
\hline Fiber, g/L & 4.10 \\
\hline Protein, $\mathrm{g} / \mathrm{L}$ & 0.40 \\
\hline Total carbohydrates, g/L & 480.50 \\
\hline Sodium, mg/L & 54.00 \\
\hline Potassium, mg/L & 324.00 \\
\hline Vitamin $\mathrm{A}, \mathrm{mg} / 100 \mathrm{~mL}$ & 23.60 \\
\hline Vitamin D, mg/mL & 0.12 \\
\hline Vitamin $\mathrm{C}, \mathrm{mg} / \mathrm{mL}$ & 146.10 \\
\hline
\end{tabular}

\section{Sensory analysis}

In Tables 4 and 5, the results of the sensory test were tabulated as to the organoleptic characteristics of odor and taste of the 20 panelists for the three samples. According to the order of preference, the first position was given the value of 4 points, the second 3.5 and the third 2.5 points. The codes of the samples were: 125, 238 and 346.

Table IV. Sensory test data regarding odor

\begin{tabular}{|c|c|c|}
\hline Samples & Number of trials & Average \\
\hline 125 & 69.5 & 3.475 \\
\hline 238 & 72.5 & 3.625 \\
\hline 346 & 58.0 & 2.900 \\
\hline Total & 200.0 & 10.000 \\
\hline
\end{tabular}

Table V. Sensory test data for taste

\begin{tabular}{|c|c|c|}
\hline Samples & Number of trials & Average \\
\hline 125 & 71.0 & 3.660 \\
\hline 238 & 66.5 & 3.325 \\
\hline 346 & 62.5 & 3.100 \\
\hline Total & 200.0 & 9.975 \\
\hline
\end{tabular}

After obtaining the totals of the results of the panelists for each of the three samples, we observed that the samples coded with numbers 125 and 238 were selected by the judges as the most preferred samples. The sample coded with the number 238 obtained a total of 32 judgments regarding the odor with a total score of 3,625 points, which represents $36.25 \%$ of the level of acceptability by the judges. The samples coded with the number 125 obtained a total of 34 judgments in terms of taste with a total score of 3.55 points, which represents $35.59 \%$ of the level of acceptability by the judges. As two samples were selected by the panelists, to choose one of the two, a preference test was carried out and in this the judges preferred the sample coded with the number 238.

\section{IV.CONCLUSIONS}

From the results obtained, the following conclusions can be presented: It is considered that the obtained beverage is within the established parameters, is formulated for all types of people, presents good taste, is a safe product free of pathogens having a time of conservation of around 3 months in refrigeration. The bromatological tests indicate significant presence of carbohydrates, vitamins and high content of carbon and potassium. 


\section{References}

[1] L. Inserra, G. Luciano, M. Bella, M. Scerra, C. Cilione, P. Basile, M. Lanza and A. Priolo, Effect of including carob pulp in the diet of fattening pigs on the fatty acid composition and oxidative stability of pork, Meat Science, 100, (2015), 256-261.

[2] V. Turfani, V. Narducci, A. Durazzo, V. Galli and M. Carcea, Technological, nutritional and functional properties of wheat bread enriched with lentil or carob flours, LWT - Food Science and Technology, 78, (2017), 361-366.

[3] H. El Batal, A. Hasib, A. Ouatmane, F. Dehbi, A. Jaouad and A. Boulli, Sugar composition and yield of syrup production from the pulp of Moroccan carob pods (Ceratonia siliqua L.), Arabian Journal of Chemistry, 9, (2016), S955-S959.

[4] C. Suleyman and K. Yusuf, Effects of carob (Ceratonia siliqua) pod byproduct on quail performance, egg characteristics, fatty acids, and cholesterol levels, Revista Brasileira de Zootecnia, 46, (2017), 113-117.

[5] Y. Benchikh, H. Louaileche, B. George and A. Merlin, Changes in bioactive phytochemical content and in vitro antioxidant activity of carob (Ceratonia siliqua L.) as influenced by fruit ripening, Industrial Crops and Products, 60, (2014), 298-303.

[6] Ł. Sęczyk, M. Świeca and U. Gawlik-Dziki, Effect of carob (Ceratonia siliqua L.) flour on the antioxidant potential, nutritional quality, and sensory characteristics of fortified durum wheat pasta, Food Chemistry, 194, (2016), 637-642.

[7] Durazzo, V. Turfani, V. Narducci, E. Azzini, G. Maiani and M. Carcea, Nutritional characterisation and bioactive components of commercial carobs flours, Food Chemistry, 153, (2014), 109-113.

[8] R. Gravador, G. Luciano, S. Jongberg, M. Bognanno, M. Scerra, M. Andersen, M. Lund and A. Priolo, Fatty acids and oxidative stability of meat from lambs fed carob-containing diets, Food Chemistry, 182, (2015), 27-34.

[9] B. Biernacka, D. Dziki, U. Gawlik-Dziki, R. Różyło, M. Siastała, Physical, sensorial, and antioxidant properties of common wheat pasta enriched with carob fiber, LWT, 77, (2017), 186-192.

[10] M. Benković, A. Belščak-Cvitanović, I. Bauman, D. Komes and S. Srečec, Flow properties and chemical composition of carob (Ceratonia siliqua L.) flours as related to particle size and seed presence, Food Research International,100, (2017), 211-218.

[11] J. Jaimes, A. Acosta, C. Severiche, Y. Marrugo and E. Bedoya, Evaluation of the Functional Properties of Prosopis juliflora Protein Concentrate Obtained by Different Methods, International Journal of Engineering and Technology, 9, (2017), 3841-3847.

[12] Y. Marrugo, C. Vargas, C. Severiche, J. Jaimes and E. Bedoya, Evaluation of the Functional Properties of Bean Starch Zaragoza (Phaseolus lunatus) White Variety in a Food Type Sausage, International Journal of Engineering and Technology, 9, (2017), 3674 3679.

[13] Y. Marrugo, D. Ramirez, N. Trujillo, C. Severiche and J. Jaimes, Development of a Scalded Meat Product Added with Modified Bean Starch Zaragoza (Phaseolus lunatus) Red Variety, Contemporary Engineering Sciences, 10, (2017), 1473 - 1483.

[14] Y. Marrugo, I. Rios, C. Martínez, C. Severiche and J. Jaimes, Elaboration of a compote type food using the starch of the Zaragoza bean (Phaseolus lunatus) as a thickener, Journal of Agricultural and Environmental Research, 8, (2017), $119-125$.

[15] Baldiris, Y. Marrugo, C. Severiche, J. Jaimes, W. Fong, L. Vargas, E. Bedoya and H. Cohen, Delayed Organoleptic Maturation of Tomato Variety Milano (Lycopersicum esculentum Mill) Using Giberelina, International Journal of ChemTech Research, 10, (2017), $1032-1037$

[16] J. Jaimes, J. Torres and C. Severiche, Analysis of the quality of a blanched meat product made with Prosopis Juliflora flour, Ingenium. $9,(2015), 21-28$.

[17] Y. Marrugo, C. Severiche and J. Jaimes, Development of a Food Product Type Based Sauce Egg plant (Solanum melongena), International Journal of ChemTech Research, 10, (2017), 567-571.

[18] I. Diaz, M. Ahumedo, E. Bedoya, L. Ballesteros, C. Diaz,, C. Severiche and A. Torregroza, Effect of Transpiration in Post-Post-Stat Condition on the Agroindustrial Quality of Chrysobalanus icaco L Fruit Variety, Contemporary Engineering Sciences, 10, (2017), $1517-1527$

[19] Y. Marrugo, C. Blanco, C. Severiche and J. Jaimes, Effect of Acetylation of Bean Starch Zaragoza (Phaseolus lunatus) Red Variety on its Functional Properties, International Journal of ChemTech Research, 10, (2017), 506-514.

[20] Y. Marrugo, P. Montero and M. Duran, Nutritional Evaluation of Concentrated Protein of Phaseolus lunatus and Vigna unguiculata, Technological Information, 27, (2016), 107-114.

[21] J. Jaimes, D. Restrepo and D. Acevedo, Preparation and determination of the functional properties of the trupillo proteic concentrated (Prosopis juliflora), Biotechnology in the Agricultural and Agroindustrial Sector, 12, (2014), 144-152.

[22] J. Jaimes, I. Rios and C. Severiche, Nanotechnology and its applications in the food industry, Food Today, 25, (2017), 51- 76.

[23] P. Montero, Y. Marrugo and L. Julio, Protein Quality of Rice Drinks Fortified with Bovine and Porcine Blood Plasma, Journal National Faculty of Agronomy, 68, (2015), 7487-7496.

[24] Y. Marrugo, P. Montero and M. Duran, Functional properties of protein concentrates of Phaseolus lunatus and Vigna unguiculata, Vitae, 19, (2012), S403-S405.'

[25] R. Coda, J. Varis, M. Verni, C. Rizzello and K. Katina, Improvement of the protein quality of wheat bread through faba bean sourdough addition, LWT - Food Science and Technology, 82, (2017), 296-302. 